\title{
Spatial Spillover Effect of Government Public Health Spending on Regional Economic Growth during the COVID-19 Pandemic: An Evidence from China
}

\author{
Xiaofei Li $\mathbb{D}^{1,2}$ Fen Chen, ${ }^{3}$ and Songbo $\mathrm{Hu}^{1}{ }^{4}$ \\ ${ }^{1}$ Zhuhai Da Hengqin Science and Technology Development Co., Ltd., Zhuhai 519031, China \\ ${ }^{2}$ Hengqin Finance Research Institute of Jilin University, Zhuhai 519031, China \\ ${ }^{3}$ School of Finance, Hubei University of Economics, Wuhan 430025, China \\ ${ }^{4}$ Jiangxi Province Key Laboratory of Preventive Medicine, School of Public Health, Nanchang University, \\ Nanchang 330019, China \\ Correspondence should be addressed to Songbo Hu; husbo0910@ncu.edu.cn
}

Received 16 January 2021; Revised 4 February 2021; Accepted 5 March 2021; Published 18 March 2021

Academic Editor: Baogui Xin

Copyright (c) 2021 Xiaofei Li et al. This is an open access article distributed under the Creative Commons Attribution License, which permits unrestricted use, distribution, and reproduction in any medium, provided the original work is properly cited.

\begin{abstract}
The COVID-19 pandemic, which was first reported at the end of 2019, has had a massive impact on the Chinese economy and society. The pandemic has seriously tested the emergency management capabilities of the Chinese government regarding public health. Based on the panel data of 31 provinces in China for the period of 2006-2019, this paper examines the impacts of government public health spending on regional economic growth. Furthermore, the possibility of spatial spillover effects of government public health spending is investigated through spatial econometric analysis. Government public health spending and regional economic growth have significant positive spatial correlation and spatial agglomeration effects. The indicator of government public health spending significantly promotes regional economic growth. In addition, it significantly promotes the economic growth of neighboring areas through certain spatial spillovers.
\end{abstract}

\section{Introduction}

The COVID-19 pandemic was first reported in Wuhan, Hubei Province, China, in December 2019 and has subsequently placed pressure on both economic and social conditions. The resulting recession could be the deepest since World War II. Economic growth has weakened due to trade tensions between the US and China that preceded the transmission of COVID-19 [1]. The pandemic also poses a serious threat to human health and life, resulting in negative economic growth in the first quarter for the entirety of China. As of 19 June 2020, the number of COVID-19 confirmed cases was 83,299 . The pandemic has also tested the Chinese public disease prevention and control system. The Chinese government has launched a first-level emergency plan to address this disaster. A large number of medical staff and large quantities of medical instruments were sent to Hubei Province and the city of Wuhan. There are many similarities between COVID-19 and SARS in 2003. Both are highly contagious diseases that can be transmitted by respiratory droplets [2]. Both diseases have also affected the formulation of public health policies. Thus, it is important to establish a strong public health and epidemic prevention system to address public health emergencies and ensure that the economy is running well.

Despite the initial responses, several disadvantages remain after the outbreak of the pandemic. The mechanism of reporting the disease was not smooth at the beginning of the pandemic. Preventive and health care measures remain imperfect. Government public health spending is unreasonable, and institutions are not well prepared with medical supplies. Nonetheless, some traditional economically powerful provinces, such as Jiangsu, Zhejiang, and Guangdong, implemented first-level responses to public health 
emergencies during the first outbreak to improve the cure rate, reduce the mortality rate, and resume production and work. The formulation and implementation of public health policy are related to the improvement of people's livelihood and the increase of people's physical well-being, which affects the level of national education and skills [3]. In the last decade, China has become the second-largest economy in the world. Its comprehensive national strength has significantly improved, and life expectancy has increased. Government public health spending has played an important role in Chinese economic growth and in building a well-off society. The policy "Healthy China 2030 Plan Outline," released by the Fifth Plenary Session of the 18th Central Committee of the CPC, puts forward the strategic theme of coconstruction/sharing and national health to comprehensively improve the health level of all the nation's people and promote the accumulation of healthy human capital in China. In the ongoing COVID-19 pandemic, it is currently very meaningful to study the impact of public health expenditure on economic growth.

In this paper, we focus on the key points: whether the government public health spending of provincial regions in China has changed, whether the contribution to regional economic growth has significantly improved, and whether there is a spatial spillover effect of government public health spending.

\section{Literature Review}

Against the background of the Chinese new normal economy, the promotion of sound and rapid economic development has been studied from different perspectives. From the perspective of industrial capital, public health spending, fixed asset investment, and technological innovation are conducive to the formation of industrial agglomeration, which promotes economic development. From the perspective of human capital, the reasonable distribution of medical and health resources can effectively promote human health quality and indirectly improve labor production efficiency, which improves the economic growth rate. From the macroeconomic level, the health factor is the catalyst of economic growth. Barro [4] established a health demand model based on the three elements of health factors, education investment, and material capital and analyzed the role of these factors in promoting economic growth. Grossman [5] introduced health capital as an endogenous variable into the health demand model and analyzed the contribution of health as a utility function and a production function in the model. From the microeconomic level, government spending on health care can well control the level of human capital. Newhouse [6] confirmed that government spending on public health has played a significant role in GDP growth. Mushkin [7] proposed that increasing public health spending easily forms healthy human capital, thus forming high-efficiency economic output.

From the perspective of empirical analysis, Narayan et al. [8] used panel data of Asian countries from 1974 to 2007 to conduct cointegration analysis on government public health spending and GDP growth, indicating that government public health spending significantly promotes per capita GDP growth. Du et al. [9] established the distribution lag model of government health expenditure and concluded that the influence coefficient of government health input on the national economy is $0.42 \%$ and that government health input makes a clear contribution to economic growth. Bernet and Singh [10] built models of operating efficiencies for 5 core public health activities to analyze economies of scale. They concluded that consolidation or regionalization might lower the cost per unit for select public health activities, which can further improve the public's health. Man et al. [11] introduced a time series model that used per capita GDP and per capita total health expenditure from 214 countries and regions in the world. The empirical analysis indicated that the influencing factors of per capita GDP should be more detailed. Mujtaba et al. [12] used panel data from 28 OECD economies from 2002 to 2018 to test the influence of environmental pollutants, economic growth, and public health. They concluded that investment in renewable energy can improve healthcare and promote economic growth. Moti and Goon [13] examined the intricate balance between health and the economy during the breakout of the COVID-19 pandemic with an econometric model. Based on the results, they gave some policy options and strategies to implement to protect health and promote economic recovery. Aisa and Pueyo [14] established an endogenous growth model and confirmed, with relevant data from developed countries, that government public health spending has a significant negative effect on economic growth. Eggoh et al. [15] selected data from typical Asian countries and used a dynamic panel model to construct a growth model. They found that government health expenditure is not conducive to promoting economic growth and, in fact, has a reverse effect on economic growth. Liu and Zhang [16] constructed a panel data model to empirically analyze data from 31 provinces in China and concluded that the indirect production expenditure in public health input has a negative effect on economic growth. In the selection of econometric models, most studies use the ordinary panel data model and fail to refine the indicators of public health spending when selecting explanatory variables. Some studies are measured by the total volume. However, the factors of economic growth cannot completely rely on total volume, and the influence of per capita factors should be considered. Moreover, the formulation of government public health policies is also affected by population factors. There is a spatial spillover effect on the surrounding provinces. Based on the above analysis, this paper intends to refine some indicators and investigate the spatial effect of public health spending on economic growth.

Tao and Wang [17] analyzed the mechanism of government public health spending and economic growth and pointed out that government public health spending directly and indirectly affects the level of economic development by improving the quality of workers, increasing social fixed capital investment, and improving the abilities of scientific and technological innovation. Therefore, government public health spending not only reflects the attention of the local government to medical care and health but also, to a certain 
degree, reflects the level of medical service and residents' health awareness [18]. This paper examines the impact of public health input factors on economic growth, including the following three issues: whether there is spatial autocorrelation between public health spending and economic growth, whether the spatial spillover effect of public health spending on economic growth is significant, and which factors related to national health quality exert a significant impact on economic growth.

\section{Methodology}

3.1. Model Specification. Most of the existing studies consider an ordinary panel data model to construct their methodology, although some also consider a dynamic panel data model with a lag effect. The traditional panel data model usually assumes that the data from different sectors should be independent. However, this assumption is not true for the research object of this paper. There is a spatial dependence between public health spending and economic growth, so it is necessary to introduce a spatial econometric model. The advantage of this approach is that the estimation result is more effective if the spatial-temporal characteristics are fully considered. There is obvious path dependence between government public health spending and regional economic growth [19]. Therefore, to accurately grasp the impact of government public health spending on regional economic growth, it is necessary to choose the spatial econometric model. The formula of spatial econometrics can be expressed as follows:

$$
Y_{i, t}=\rho W Y_{i, t}+X_{i, t} \beta+W X_{i, t} \theta+\mu_{i}+\gamma_{t}+\varepsilon_{i, t} .
$$

In this formula, $\rho$ is the spatial autocorrelation coefficient, $W$ is the spatial weight matrix, $W Y, W X$ are spatial lag terms, and $\varepsilon_{i, t}$ is the error term satisfying $\varepsilon_{i, t} \sim N\left(0, \sigma^{2} I_{n}\right)$. There are three types of spatial econometric models: the spatial autoregressive model (SAR), spatial error model (SEM), and spatial Durbin model (SDM).

3.2. Variable Selection. Per capita GDP is an important indicator to measure the level of economic growth and is selected as the explained variable. According to the results of the existing literature [20-23], to quantify the emphasis of government on public health, this paper selects government public health spending as an explanatory variable. Furthermore, as noted by Hazwan [24], there are many ways to capture human capital. For example, Barro [4] used a combination of the enrollment rate, life expectancy, and birth rate as proxies for human capital. Li and Huang [25] pointed out that human resources related to public health must be considered. They suggested using the number of medical staff as a proxy for human capital. As an important factor of the economic system, the birth rate has a long-term, stable relationship with economic development. The increase in birth rate can optimize the Chinese population structure and improve the overall quality of the whole population [26]. Before the full liberalization of the Chinese two-child policy in 2015, most research conclusions showed a negative correlation between birth rate and economic development. However, with the adjustment of population policy, the demographic dividend has transformed again into the engine of economic growth, thereby promoting economic growth. At the same time, the continuous promotion of urbanization has resulted in increasingly substantial investment in infrastructure construction in China. Such investment directly affects the national physical quality, education level, and scientific and technological innovation, which indirectly affect the development of the regional economy. Some results have shown that the urbanization rate plays a clear role in promoting economic growth [27]. To fully reflect healthy resources, following $[20,24,28]$, fixed investment, human capital, medical scale, urbanization, and population size are chosen as control variables. The symbols and descriptions of each variable are shown in Table 1.

3.3. Data Sources. The original panel data of 31 provinces in China from 2006 to 2019 are chosen from the China Science and Technology Statistical Yearbook, China Health and Family Planning Statistical Yearbook, China Statistical Yearbook, and the National Economic and Social Development Statistical Bulletin (due to the lack of statistical data, Hong Kong, Macao, and Taiwan are not included in the research). To eliminate the influence of currency, GDP data are adjusted based on 2005. Considering the influence of dimensionality and heteroscedasticity on the model, the corresponding data are processed with a natural logarithm. For missing data, we use the method of local polynomial interpolation. The summary statistics of all variables are shown in Table 2.

3.4. Spatial Autocorrelation Indicators. To test whether the public health spending of 31 provinces in China is suitable for the spatial econometric model, it is necessary to test the spatial correlation of variables. Moran's $I$ in econometrics is used in this paper. The formula of global Moran's $I$ at the national level is given as follows:

$$
I_{G}=\frac{n \sum_{i=1}^{n} \sum_{j=1}^{n} w_{i j}\left(x_{i}-\bar{x}\right)\left(x_{j}-\bar{x}\right)}{\sum_{i=1}^{n} \sum_{j=1}^{n} w_{i j} \sum_{j=1}^{n}\left(x_{i}-\bar{x}\right)^{2}} .
$$

In formula (2), $I_{G}$ represents the global Moran's $I ; n$ is the number of regions; $x_{i}$ and $x_{j}$ represent, respectively, the values of region $i$ and region $j$; and $w_{i j}$ is the spatial weight matrix. The value of Moran's $I$ changes from -1 to 1 . If Moran's $I$ is positive, it shows a positive spatial correlation. If Moran's $I$ is negative, it shows a negative spatial correlation [29]. To further study the spatial agglomeration effect in different regions, the local Moran's $I$ is used. The formula for the local Moran's $I$ is given in the following:

$$
I_{L}=\frac{n\left(x_{i}-\bar{x}\right) \sum_{j=1}^{n} w_{i j}\left(x_{j}-\bar{x}\right)}{\sum_{j=1}^{n}\left(x_{i}-\bar{x}\right)^{2}} .
$$

In formula (3), $I_{L}$ represents the local Moran's $I$, and the other variables are the same as those in formula (2). A local 
TABLE 1: Variable descriptions.

\begin{tabular}{|c|c|c|c|c|}
\hline Variable & Reaction factor & Symbol & Description & Unit \\
\hline Explained variable & Level of economic development & pgdp & GDP per capita & Thousand yuan \\
\hline \multirow{2}{*}{ Explanatory variable } & Public health expenditure & pph & Government spending on public health & Billion yuan \\
\hline & Fixed investment & fi & Fixed asset investment & 10 billion yuan \\
\hline \multirow{4}{*}{ Control variable } & Human capital & hc & Average of health technical staff & - \\
\hline & Medical scale & $\mathrm{mc}$ & Average of medical beds & - \\
\hline & Urbanization & ur & Urbanization rate & $\%$ \\
\hline & Population size & $\mathrm{rp}$ & Birth rate & $\%$ \\
\hline
\end{tabular}

TABLE 2: Summary statistics of all variables.

\begin{tabular}{|c|c|c|c|c|c|}
\hline Variable & Max & Min & Mean & Std. dev & Obs \\
\hline pgdp & 164.22 & 5.75 & 43.92 & 26.70 & 434 \\
\hline pph & 15.65 & 0.07 & 2.71 & 2.37 & 434 \\
\hline $\mathrm{Fi}$ & 59.07 & 0.23 & 13.16 & 12.01 & 434 \\
\hline $\mathrm{Hc}$ & 15.46 & 2.10 & 5.47 & 1.93 & 434 \\
\hline Mc & 7.65 & 1.69 & 4.51 & 1.39 & 434 \\
\hline Ur & 89.60 & 21.13 & 53.66 & 14.28 & 434 \\
\hline $\mathrm{Rp}$ & 17.89 & 5.36 & 11.37 & 2.71 & 434 \\
\hline
\end{tabular}

Moran scatter diagram intuitively expresses local spatial autocorrelation. A two-dimensional graph is drawn to express the relationship between a spatial unit and its surrounding spatial units [30]. The first quadrant comprises a fully positive correlation, and the third quadrant comprises a fully negative correlation. The second quadrant indicates that a region has a low indicator, while its neighbors have a high indicator. The fourth quadrant represents that a region has a high indicator, while its neighbors have a low indicator [31]. In this paper, we select the adjacent space weight matrix. If region $i$ and region $j$ have common edges or vertices, then $w_{i j}=1$; otherwise, $w_{i j}=0$.

We use the STATA 15 software to test the global Moran's I of pgdp of 31 provinces in China from 2006 to 2019 and report the results in Table 3. Moran's $I$ is greater than 0 and significant at the $1 \%$ level. This result indicates that the data are subject to significant positive spatial correlation and have spatial agglomeration effects. Hence, it is necessary to consider a spatial econometric model for explanatory and explained variables for its own and neighborhood variables. The Chinese economy was affected by the global financial crisis from 2007 to 2010, which greatly affected both Chinese investment and import/export trade and the healthy development of the economy due to the existence of domestic economic structural contradictions. From 2011 to 2013, the Chinese economy began to recover from the global financial crisis. By expanding domestic demand, adjusting the economic structure, and developing high-tech industries, the country has achieved regional economic growth. In 2011, China became the second-largest economy in the world. From 2014 to 2019, the Chinese economy converted from a high-speed growth stage to a high-quality development stage. In the process of building a modern economic system, we should not only pay attention to the development of the real economy but also pay attention to the construction of public utilities such as the public health system.
TABLE 3: Global Moran's I results for pgdp

\begin{tabular}{lc}
\hline Year & pgdp \\
\hline 2006 & $0.406(4.189)^{* * *}$ \\
2007 & $0.399(4.080)^{* * *}$ \\
2008 & $0.405(4.072)^{* * *}$ \\
2009 & $0.403(4.030)^{* * *}$ \\
2010 & $0.414(4.100)^{* * *}$ \\
2011 & $0.410(4.044)^{* * *}$ \\
2012 & $0.394(3.891)^{* * *}$ \\
2013 & $0.381(3.678)^{* * *}$ \\
2014 & $0.362(3.598)^{* * *}$ \\
2015 & $0.360(3.576)^{* * *}$ \\
2016 & $0.371(3.696)^{* * *}$ \\
2017 & $0.398(3.948)^{* * *}$ \\
2018 & $0.388(3.851)^{* * *}$ \\
2019 & $0.330(3.403)^{* * *}$ \\
* $^{* * *}, * *$, and ${ }^{*}$ indicate statistical significance at the $1 \%, 5 \%$, and $10 \%$ levels, \\
respectively. The $z$ statistic is in parentheses.
\end{tabular}

Figure 1 shows local Moran scatter diagrams of pgdp and pph in 2015 and 2019. Most scatter plots are located in the first and third quadrants, indicating that spatial distributions of government public health spending and regional economic growth are not randomly distributed but display a clear spatial agglomeration. In addition, the eastern coastal areas of Shanghai, Jiangsu, Zhejiang, Shandong, Beijing, Tianjin, Fujian, and other provinces show a "high-high" agglomeration trend.

3.5. Direct and Indirect Effects. In this subsection, we further decompose the model by introducing the method of direct, indirect, and total effects. We rewrite formula (1) in the form of a matrix equation:

$$
Y=\rho W Y+X \beta+W X \theta+\alpha+\varepsilon .
$$




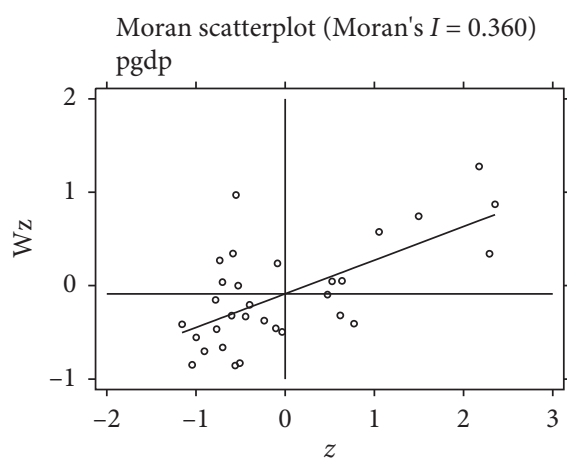

(a)

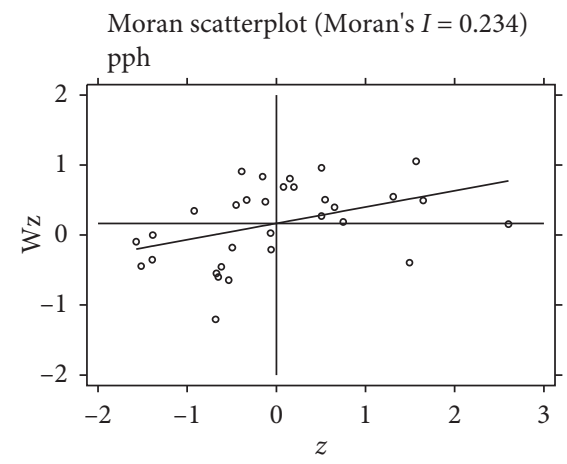

(c)

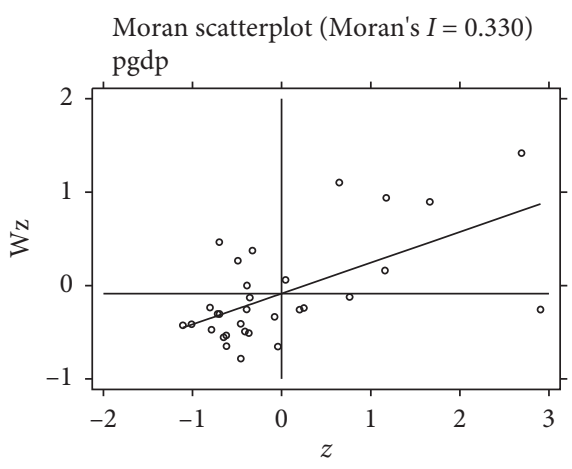

(b)

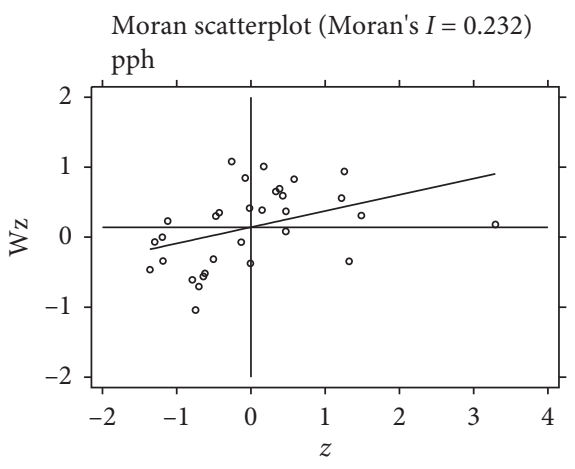

(d)

Figure 1: Local Moran scatter diagrams of pgdp and pph. (a) 2015 pgdp. (b) 2019 pgdp. (c) 2015pph. (d) 2019 pph.

The matrix equation (4) is transformed into the inverse matrix equation as follows:

$$
Y=(I-\rho W)^{-1} \alpha+(I-\rho W)^{-1}(X \beta+W X \theta)+(I-\rho W)^{-1} \varepsilon .
$$

Taking the derivative of vector $X$ on both sides of formula (5), we obtain a partial differential matrix equation as follows:

$$
\left[\begin{array}{ccc}
\frac{\partial Y}{\partial X_{1 k}} \cdots & \frac{\partial Y}{\partial X_{n k}}
\end{array}\right]=\left[\begin{array}{ccc}
\frac{\partial Y_{1}}{\partial X_{1 k}} & \cdots & \frac{\partial Y_{n}}{\partial X_{1 k}} \\
\cdots & \cdots & \cdots \\
\frac{\partial Y_{n}}{\partial X_{1 k}} & \cdots & \frac{\partial Y_{n}}{\partial X_{n k}}
\end{array}\right]=(I-\rho W)^{-1}\left[\begin{array}{cccc}
\beta_{k} & W_{12} \theta_{k} & \cdots & W_{1 n} \theta_{k} \\
W_{21} \theta_{k} & \beta_{k} & \cdots & W_{2 n} \theta_{k} \\
\cdots & \cdots & \cdots & \cdots \\
W_{n 1} \theta_{k} & W_{n 2} \theta_{k} & \cdots & \beta_{k}
\end{array}\right]
$$

The mean value of the diagonal elements of the right matrix is defined as a direct effect, and the mean value of the sum of nondiagonal elements in each row or each column is defined as an indirect effect (also known as a spillover effect). The sum of the direct effect and indirect effect is the total effect, which is the comprehensive effect of the explanatory variable on the explained variable.

\section{Empirical Analysis}

4.1. Estimation of Nonspatial Panel Data. First, to choose a suitable econometric model, we operate pool ordinary least squares (OLS) regression with nonspatial panel data. The regression results of the nonspatial model are shown in Table 4.

As seen in Table 4, the result of the $\mathrm{F}$ test with spatial fixed effects and time fixed effects is significant at the 1\% level, implying that there are spatial and time fixed effects in the model. Therefore, SDM is chosen to analyze the spatial panel data.

4.2. Estimation of SDM at National Level. Next, we test to estimate SDM at the national level. To verify whether SDM can be simplified to SAR and SEM, we should report the 
TABLE 4: Estimation results of nonspatial panel data.

\begin{tabular}{|c|c|c|c|c|}
\hline \multirow{2}{*}{ Variable } & \multicolumn{4}{|c|}{ Classification of fixed effect models } \\
\hline & Pool OLS & Spatial fixed effects & Time fixed effects & Spatial-time-fixed effects \\
\hline $\operatorname{lnpph}$ & $\begin{array}{c}0.1699^{* * *} \\
(0.0325)\end{array}$ & $\begin{array}{c}0.3220^{* * *} \\
(0.0160)\end{array}$ & $\begin{array}{c}-0.1153^{* * *} \\
(0.0338)\end{array}$ & $\begin{array}{c}-0.0875^{* *} \\
(0.0358)\end{array}$ \\
\hline $\ln f i$ & $\begin{array}{l}-0.0032 \\
(0.0290) \\
\end{array}$ & $\begin{array}{c}0.1713^{* * *} \\
(0.0200) \\
\end{array}$ & $\begin{array}{c}0.1413^{* * *} \\
(0.0264) \\
\end{array}$ & $\begin{array}{c}0.1295^{* * *} \\
(0.0278)\end{array}$ \\
\hline $\operatorname{lnh} c$ & $\begin{array}{c}0.6816^{* * *} \\
(0.0973) \\
\end{array}$ & $\begin{array}{l}0.1107^{*} \\
(0.0619)\end{array}$ & $\begin{array}{c}0.8126^{* * *} \\
(0.0815) \\
\end{array}$ & $\begin{array}{c}0.7579^{* * *} \\
(0.0852) \\
\end{array}$ \\
\hline $\operatorname{lnmc}$ & $\begin{array}{c}0.0009 \\
(0.0822)\end{array}$ & $\begin{array}{c}0.0031 \\
(0.0527)\end{array}$ & $\begin{array}{c}-0.4054^{* * *} \\
(0.0747)\end{array}$ & $\begin{array}{c}-0.4718^{* * *} \\
(0.0810)\end{array}$ \\
\hline lnur & $\begin{array}{c}1.0168^{* * *} \\
(0.0871) \\
\end{array}$ & $\begin{array}{c}0.4527^{* * *} \\
(0.1250)\end{array}$ & $\begin{array}{c}0.9390 \\
(0.7283) \\
\end{array}$ & $\begin{array}{c}1.0274^{* * *} \\
(0.0775)\end{array}$ \\
\hline $\ln r p$ & $\begin{array}{l}0.1215^{* *} \\
(0.0539)\end{array}$ & $\begin{array}{l}-0.0204 \\
(0.0473)\end{array}$ & $\begin{array}{c}-0.0058^{* * *} \\
(0.04622)\end{array}$ & $\begin{array}{c}0.0217 \\
(0.0471)\end{array}$ \\
\hline$R^{2}$ & 0.8559 & 0.9721 & 0.8166 & 0.9062 \\
\hline$F$ statistic & $429.53^{* * *}$ & $115.58^{* * *}$ & $115.58^{* * *}$ & 11.15 \\
\hline
\end{tabular}

${ }^{* * *},{ }^{* *}$, and ${ }^{*}$ indicate statistical significance at the $1 \%, 5 \%$, and $10 \%$ levels, respectively. The numbers in the coefficient parentheses are standard errors.

results of the Wald and LR tests of the model. The null hypotheses of the Wald test and LR test are $H_{0}^{1}: \theta=0$ and $H_{0}^{2}: \theta+\rho \beta=0$, respectively [32]. To determine the fixed effect model or random effect model, the Hausman test should be implemented. The results of the Wald, LR, and Hausman tests are listed in Table 5.

Both the Wald and the LR tests reject the null hypotheses, indicating that SDM should be recommended. According to the Hausman test, $\mathrm{chi}^{2}=26.52>0$ and passes the significance test at the level $1 \%$, implying that the fixed effect model is superior to the random effect model. According to the above statements, SDM with fixed effects is the best model to analyze the spatial panel data in this paper. The fixed effect model is divided into spatial fixed effects, time fixed effects, and spatial-time-fixed effects. To select a better model, we test three models individually and report the results in Table 6 .

Table 6 shows that the significance of rho and the variables of the time fixed effect model are higher than those of the other models. In other words, a time fixed effect model is recommended to investigate the impact of government public health spending on regional economic growth. The SDM results show that the spatial agglomeration of government public health spending exerts a significant influence on regional economic growth. The explanatory variable $\mathrm{pph}$ has a significant positive impact on local economic growth. The elasticity coefficient is 0.1671 . This result implies that, for every $1 \%$ increase in government public health spending, economic growth will increase by $0.1671 \%$. The control variable rp exerts a significant negative impact on local economic growth. In addition, the spatial autoregression coefficient (rho) reveals that it has a significant positive correlation with regional economic growth. Moreover, the $R^{2}$ of the SDM is larger than that of the pool OLS model, indicating that the spatial econometric model is more suitable for this paper.
TABLE 5: Result of Wald, LR, and Hausman tests.

\begin{tabular}{lcc}
\hline Test & Statistics & $p$-value \\
\hline Wald spatial lag & 26.93 & 0.000 \\
Wald spatial error & 30.97 & 0.000 \\
LR spatial lag & 16.39 & 0.018 \\
LR spatial error & 32.87 & 0.000 \\
Hausman & 26.52 & 0.001 \\
\hline
\end{tabular}

4.3. Spillover Effects. Furthermore, $\mathrm{Xu}$ and Wang [30] pointed out that, in SDM, the regression coefficient of the explanatory variable cannot directly reflect its effects on the explained variable. Therefore, it is necessary to employ spatial effect decomposition. We show the decomposition result of spatial effects under time fixed effects in Table 7.

As shown in Table 7, the direct effects of all variables are significant at the $5 \%$ level, which indicates that the core indicators pph, fi, hc, and ur can significantly promote regional economic growth. Against the background of the new normal of the Chinese economy, the factors related to the health of human capital become increasingly important. Without healthy human capital, there is no motivating force to transform into economic growth, which also shows that economic growth contains the recognition of health awareness as well as scientific and technological innovation. Although the birth rate (rp) has a clear reverse effect on the growth of the regional economy, the coefficient of its spatial lag term is significantly positive at the $1 \%$ level, indicating that the excessive population base in the current period hinders economic growth. However, the lag effect will be transformed into a positive effect over time. Therefore, the birth rate will indirectly promote economic growth.

For the spatial spillover effects in Table 7, the effects of variables pph, hc, and ur are significantly positive, which 
TABLE 6: Estimation result of SDM at national level.

\begin{tabular}{|c|c|c|c|}
\hline & \multicolumn{3}{|c|}{ Classification of fixed effect models } \\
\hline & Spatial fixed effects & Time fixed effects & Spatial-time-fixed effects \\
\hline Lnpph & $\begin{array}{c}0.3015^{* * *} \\
(0.0221) \\
\end{array}$ & $\begin{array}{c}0.1671^{* * *} \\
(0.0323) \\
\end{array}$ & $\begin{array}{r}0.1615^{* * *} \\
(0.0331) \\
\end{array}$ \\
\hline Lnfi & $\begin{array}{c}0.1329^{* * *} \\
(0.0193)\end{array}$ & $\begin{array}{c}0.1350^{* * *} \\
(0.0235)\end{array}$ & $\begin{array}{c}0.1436^{* * *} \\
(0.0202)\end{array}$ \\
\hline Lnhe & $\begin{array}{l}0.1371^{* *} \\
(0.0570) \\
\end{array}$ & $\begin{array}{c}0.8791^{* * *} \\
(0.0731) \\
\end{array}$ & $\begin{array}{l}0.1130^{*} \\
(0.0586)\end{array}$ \\
\hline Lnmc & $\begin{array}{l}-0.0560 \\
(0.0519) \\
\end{array}$ & $\begin{array}{c}-0.4021^{* * *} \\
(0.0772) \\
\end{array}$ & $\begin{array}{c}0.0017 \\
(0.0514)\end{array}$ \\
\hline Lnur & $\begin{array}{c}0.3812^{* * *} \\
(0.1098) \\
\end{array}$ & $\begin{array}{c}0.7664^{* * *} \\
(0.0787) \\
\end{array}$ & $\begin{array}{c}0.3222^{* * *} \\
(0.1087) \\
\end{array}$ \\
\hline Lnrp & $\begin{array}{c}0.0109 \\
(0.0447) \\
\end{array}$ & $\begin{array}{c}-0.1415^{* *} \\
(0.0606) \\
\end{array}$ & $\begin{array}{c}0.0408 \\
(0.0445) \\
\end{array}$ \\
\hline$W^{*} \ln p p h$ & $\begin{array}{c}-0.1676^{* * *} \\
(0.0317) \\
\end{array}$ & $\begin{array}{l}0.2457^{* *} \\
(0.0587) \\
\end{array}$ & $\begin{array}{l}-0.0162 \\
(0.0360)\end{array}$ \\
\hline$W^{*} \ln f i$ & $\begin{array}{c}0.0120 \\
(0.0349) \\
\end{array}$ & $\begin{array}{c}-0.1284^{* * *} \\
(0.0463) \\
\end{array}$ & $\begin{array}{l}0.1363^{* *} \\
(0.0555)\end{array}$ \\
\hline$W^{*} \operatorname{lnh} c$ & $\begin{array}{c}-0.2353^{* *} \\
(0.1179) \\
\end{array}$ & $\begin{array}{l}-0.1184 \\
(0.1433) \\
\end{array}$ & $\begin{array}{l}-0.1640 \\
(0.1288)\end{array}$ \\
\hline$W^{*} \ln m c$ & $\begin{array}{c}0.2240^{* *} \\
(0.1033) \\
\end{array}$ & $\begin{array}{l}-0.0677 \\
(0.1462)\end{array}$ & $\begin{array}{l}0.1850^{*} \\
(0.1063) \\
\end{array}$ \\
\hline$W^{*} \ln u r$ & $\begin{array}{l}-0.1236 \\
(0.1982)\end{array}$ & $\begin{array}{c}0.0148 \\
(0.0771) \\
\end{array}$ & $\begin{array}{c}-0.6481^{* * *} \\
(0.2233) \\
\end{array}$ \\
\hline$W^{*} \ln r p$ & $\begin{array}{l}-0.1078 \\
(0.0770) \\
\end{array}$ & $\begin{array}{c}0.2931^{* * *} \\
(0.0692) \\
\end{array}$ & $\begin{array}{l}-0.0316 \\
(0.0925) \\
\end{array}$ \\
\hline $\begin{array}{l}\text { Rho } \\
R^{2} \\
\text { Log-likelihood }\end{array}$ & $\begin{array}{c}0.4324^{* * *} \\
0.9752 \\
567.6973\end{array}$ & $\begin{array}{c}0.2581^{* * *} \\
0.8719 \\
465.3824\end{array}$ & $\begin{array}{c}0.2108 \\
0.9702 \\
610.6094\end{array}$ \\
\hline
\end{tabular}

${ }^{* * *},{ }^{* *}$, and ${ }^{*}$ indicate significance at the $1 \%, 5 \%$, and $10 \%$ levels, respectively. The numbers in the coefficient parentheses are standard errors.

TABLE 7: Direct, indirect, and total effects of SDM with time fixed effects.

\begin{tabular}{|c|c|c|c|}
\hline Variable & Direct effect & Indirect effect & Total effect \\
\hline Lnpph & $0.0542(-4.55)^{* * *}$ & $0.2528(3.28)^{* * *}$ & $0.3070(1.07)$ \\
\hline Lnfi & $0.1283(5.25)^{* * *}$ & $-0.1172(-2.00)^{* *}$ & $0.0111(0.16)$ \\
\hline Lnhc & $0.8916(12.58)^{* * *}$ & $0.1470(2.11)^{* *}$ & $1.0386(5.40)^{* * *}$ \\
\hline Lnmc & $-0.4168(-6.03)^{* * *}$ & $-0.2194(-1.28)$ & $-0.6362(-3.79)^{* * *}$ \\
\hline Lnur & $0.7760(10.06)^{* * *}$ & $0.2620(2.74)^{* * *}$ & $1.0380(7.29)^{* * *}$ \\
\hline Lnrp & $-0.1249(-2.20)^{* *}$ & $0.3222(4.46)^{* * *}$ & $0.1973(2.86)^{* * *}$ \\
\hline
\end{tabular}

indicates that these indicators not only significantly promote regional economic growth in the region but also have some spillover effects. However, the total effect of explanatory pph does not pass the significance test. The direct, indirect, and total effects of control variable ur all pass the significance test at the $1 \%$ level. To develop the local economy, the government needs a considerable amount of land. In the case of a shortage of industrial land in the city, it begins to expand to the periphery of the city and drives investment and funding of major municipal construction, which promotes local economic development. Generally, the size of health care is related to the number of health technicians. If there is a high level of medical technology in a city, it tends to attract residents from surrounding areas to seek medical treatment. This phenomenon is common in big cities. Moreover, we also see that the coefficient of $\mathrm{mc}$ is negative but not significant, indicating that the number of medical beds does not necessarily hinder economic growth at the national level.

4.4. Robustness Test. In this subsection, we present the robustness test of the model. From the above analysis, we know that the SDM with time period fixed effects is the best for the panel data. Therefore, we should again operate the SDM by converting the spatial weight matrix into geographical distance and economic distance. The conversion results are listed in Table 8, which shows that, for the geographical 
TABLE 8: Robustness test of public health spending on regional economic growth.

\begin{tabular}{|c|c|c|c|c|}
\hline \multirow{2}{*}{ Variable } & \multicolumn{2}{|c|}{ Geographical distance matrix } & \multicolumn{2}{|c|}{ Economic distance matrix } \\
\hline & Coefficient & $t$ value & Coefficient & $t$ value \\
\hline Lnpph & $0.0884^{* *}$ & -2.45 & $0.1394^{* * *}$ & -6.02 \\
\hline Lnfi & $0.0891^{* * *}$ & 3.44 & $0.0829^{* * *}$ & 4.52 \\
\hline Lnhc & $0.6741^{* * *}$ & 7.33 & $0.5296^{* * *}$ & 9.78 \\
\hline Lnmc & $-0.1943^{* *}$ & -2.19 & $-0.1337^{* * *}$ & -2.67 \\
\hline Lnur & $0.7610^{* * *}$ & 10.26 & $0.7148^{* * *}$ & 14.97 \\
\hline Lnrp & $-0.1385^{* *}$ & -2.40 & $0.1343^{* * *}$ & 4.18 \\
\hline$W^{*} \operatorname{lnpph}$ & $0.2932^{* * *}$ & 3.31 & $0.1907^{* *}$ & -2.42 \\
\hline$W^{*} \ln f i$ & $-0.1126^{*}$ & -1.73 & -0.0645 & -1.33 \\
\hline$W^{*} \operatorname{lnh} c$ & -0.0778 & -0.41 & $-0.3664^{* *}$ & -1.99 \\
\hline$W^{*} \operatorname{lnmc}$ & -0.1072 & -0.60 & -1.999 & -1.38 \\
\hline$W^{*} \ln u r$ & $0.8693^{* * *}$ & 3.13 & $2.7241^{* * *}$ & 11.01 \\
\hline$W^{*} \ln r p$ & $0.4261^{* * *}$ & 3.62 & $0.5031^{* * *}$ & 4.70 \\
\hline Rho & $0.0372^{*}$ & 1.79 & $0.0768^{*}$ & 1.89 \\
\hline$R^{2}$ & 0.9442 & & 0.9628 & \\
\hline Log-likelihood & 154.1253 & & 303.5903 & \\
\hline
\end{tabular}

${ }^{* * *},{ }^{* *}$, and ${ }^{*}$ indicate significance at the $1 \%, 5 \%$, and $10 \%$ levels, respectively. The numbers in the coefficient parentheses are standard errors.

distance matrix and economic distance matrix, the result is the same as the adjacent spatial weight matrix. This result implies that government public health spending has significant spatial agglomeration and a significant positive impact on regional economic growth. In other words, the results of this paper are robust.

4.5. Estimation of SDM at Subnational Level. Due to the vast territory of China, heterogeneity among regions is prominent with respect to the natural environment, humanistic background, and location advantage. To understand the relationship between public health spending and economic growth in more detail, following concepts in the existing literature $[20,23]$, we divide the national sample into three subsamples according to geographical location: eastern (including Beijing, Tianjin, Hebei, Liaoning, Shanghai, Jiangsu, Zhejiang, Fujian, Shandong, Guangdong, and Hainan), central (including Shanxi, Jilin, Heilongjiang, Anhui, Jiangxi, Henan, Hubei, and Hunan), and western (including Sichuan, Chongqing, Guizhou, Yunnan, Shaanxi, Gansu, Qinghai, Ningxia, Tibet, Xinjiang, Guangxi, and Inner Mongolia). The SDM model is again used to test the relationship between government public health expenditure and regional economic growth, and the regression results are shown in Table 9.

The results in Table 9 show that the values of $R^{2}$ and loglikelihood are ideal. All the spatial autocorrelation coefficients are positive, implying that there is a spatial agglomeration effect of government public health spending and regional economic growth for the three subsamples. Regarding the significance of the explanatory variable, there are positive effects in the eastern and central regions, while the western region does not pass the significance test. Regarding the control variables, the coefficient of fixed asset investment in the eastern, central, and western regions is positive and passes the significance test, indicating that it promotes regional economic growth. The coefficient of the urbanization rate in the central and western regions is positive and passes the significance test, whereas it fails the
TABLE 9: SDM estimation results at the subnational level.

\begin{tabular}{|c|c|c|c|}
\hline Variable & Eastern & Central & Western \\
\hline lnpph & $\begin{array}{l}0.3183^{* * *} \\
(0.0367)\end{array}$ & $\begin{array}{c}0.1669^{* * *} \\
(0.0717)\end{array}$ & $\begin{array}{c}0.0792 \\
(0.0587)\end{array}$ \\
\hline $\ln f i$ & $\begin{array}{l}0.1670^{* * *} \\
(0.0366)\end{array}$ & $\begin{array}{c}0.1079^{* * * *} \\
(0.0372)\end{array}$ & $\begin{array}{c}0.1750^{* * * *} \\
(0.0337)\end{array}$ \\
\hline $\operatorname{lnh} c$ & $\begin{array}{r}0.1151 \\
(0.0949)\end{array}$ & $\begin{array}{l}-0.1732 \\
(0.1467)\end{array}$ & $\begin{array}{c}0.3482^{* * *} \\
(0.1072)\end{array}$ \\
\hline $\ln m c$ & $\begin{array}{l}-0.0578^{*} \\
(0.0900) \\
\end{array}$ & $\begin{array}{c}0.1418 \\
(0.1218) \\
\end{array}$ & $\begin{array}{c}0.0562 \\
(0.0818) \\
\end{array}$ \\
\hline Lnur & $\begin{array}{r}0.1121 \\
(0.2991)\end{array}$ & $\begin{array}{c}0.3924^{*} \\
(0.2323)\end{array}$ & $\begin{array}{c}0.3141^{* *} \\
(0.1407)\end{array}$ \\
\hline Lnrp & $\begin{array}{r}0.0294 \\
(0.0804)\end{array}$ & $\begin{array}{l}0.1483^{* *} \\
(0.0741)\end{array}$ & $\begin{array}{c}-0.1300^{*} \\
(0.0722)\end{array}$ \\
\hline$W^{*} \operatorname{lnpph}$ & $\begin{array}{c}-0.0059 \\
(0.0705)\end{array}$ & $\begin{array}{c}-0.1475^{*} \\
(0.0773)\end{array}$ & $\begin{array}{c}0.0688 \\
(0.0627)\end{array}$ \\
\hline$W^{*} \ln f i$ & $\begin{array}{r}0.0872 \\
(0.0959)\end{array}$ & $\begin{array}{c}0.1322^{*} \\
(0.0679)\end{array}$ & $\begin{array}{l}-0.0609 \\
(0.0518)\end{array}$ \\
\hline$W^{*} \operatorname{lnh} c$ & $\begin{array}{c}-0.1492^{*} \\
(0.1482)\end{array}$ & $\begin{array}{l}-0.0032 \\
(0.1660)\end{array}$ & $\begin{array}{r}-0.3677^{* *} \\
(0.1433)\end{array}$ \\
\hline$W^{*} \operatorname{lnmc}$ & $\begin{array}{r}0.2270 \\
(0.1550)\end{array}$ & $\begin{array}{c}0.1478 \\
(0.1440)\end{array}$ & $\begin{array}{c}0.1731 \\
(0.1270)\end{array}$ \\
\hline$W^{*} \ln u r$ & $\begin{array}{c}-0.3246 \\
(0.0 .4162)\end{array}$ & $\begin{array}{c}-0.4516 \\
(0.2776)\end{array}$ & $\begin{array}{c}-0.4492^{* *} \\
(0.2075)\end{array}$ \\
\hline$W^{*} \ln r p$ & $\begin{array}{c}-0.2155 \\
(0.1097)\end{array}$ & $\begin{array}{c}-0.2187^{* *} \\
(0.0893)\end{array}$ & $\begin{array}{c}0.0492 \\
(0.1346)\end{array}$ \\
\hline Rho & $\begin{array}{r}0.0211 \\
(0.0874)\end{array}$ & $\begin{array}{c}0.4959^{* * *} \\
(0.0682)\end{array}$ & $\begin{array}{c}0.4734^{* * *} \\
(0.0750)\end{array}$ \\
\hline$R^{2}$ & 0.9648 & 0.9763 & 0.9853 \\
\hline Log-likelihood & 188.3498 & 161.7663 & 256.0567 \\
\hline
\end{tabular}

${ }^{* * *},{ }^{* *}$, and ${ }^{*}$ indicate significance at the $1 \%, 5 \%$, and $10 \%$ levels, respectively. The numbers in the coefficient parentheses are standard errors.

significance test in the eastern region. Judging by birth rate has significantly hindered economic growth in the western region, which may be related to the rapid growth of the population in the west. Excessive population growth leads to 
uncoordinated development with economic growth, reduces the amount of wealth per capita, and exacerbates the contradiction between the labor force and employment opportunities [33].

\section{Conclusions and Suggestions}

This study uses panel data of 31 provinces in China to study the impact of government public health spending on regional economic growth. The results show that there is a clear spatial agglomeration effect of government public health spending on regional economic growth. Furthermore, government public health spending has significant promotion and spillover effects on regional economic growth. The explanatory variable shows significant spatial spillover effects. In addition, the population birth rate shows a significant negative correspondence with economic growth. However, over time, the birth rate maintains the same direction as economic growth.

Government public health spending influences people's physical fitness to guide them to obtain a high-quality education. These policies can improve the medical environment and health, municipal facilities, and other physical conditions. Additionally, cities can attract more high-level and high-quality talent and improve the technology of local regions, which can enhance technological innovation capabilities and comprehensive competitiveness to promote rapid economic growth. The Chinese economy has adjusted to the new normal. The government no longer leads the development of the market, but instead stimulates market vitality through optimization and reasonable spatial layout. With the aging of China's population, the increasing rate of the number of laborers has decelerated, and the structure of talent is unreasonable. The demand for high-quality professional and technical personnel has increased. In this environment, the Chinese economy has made a new transition from the traditional high-speed growth stage to the high-quality development stage, especially during the COVID-19 pandemic, which has severely tested the emergency response capabilities of the Chinese government and prompted the government's attention to improve public health mechanisms.

In the future, policies should be adjusted. It is necessary to expand health resources to cover the population and improve the number and professional quality of health institutions. Additionally, the government should establish the division of labor and cooperation between professional health institutions and community health institutions. Furthermore, complementary resources should be established to improve the service efficiency and level of health institutions. As the process of urbanization accelerates, it is necessary to establish sound coverage of the basic public health service system and increase the number of health technicians in the grassroots community. Government spending on public health should follow the principles of prebudget, in-process, and postaudit supervision. Such spending should be guaranteed by legal supervision, which can improve the quality of government public health construction and public health early warning mechanisms and expand the coverage of health care institutions. There is great love in the face of the catastrophe. Donations from social groups and overseas Chinese during the pandemic have played an important role in winning the battle against COVID-19. Therefore, in future medical and health reforms, public health funds should be established for public health promotion, health funding, and assistance to vulnerable groups. Social groups and overseas Chinese should be encouraged to donate appropriately. Despite the great challenges posed by this pandemic, public health institutions have made outstanding contributions. In the future, we should increase spending on public health institutions and strengthen the training of professional and technical personnel.

\section{Data Availability}

The data used to support the findings of this study are available from the corresponding author upon request.

\section{Conflicts of Interest}

The authors declare that they have no conflicts of interest.

\section{Acknowledgments}

This study was supported by the Humanities and Social Sciences Fund of the Ministry of Education of China (no. 17YJC840015), the National Natural Science Foundation of China (no. 81960618), the Foundation of Hubei Key Laboratory of Applied Mathematics (no. AM201807), the Research Project of College of Engineering and Technology Yangtze University (no. 2020KY07), and the Scientific Research Projects of Hubei Provincial Department of Education (no. B2020341).

\section{References}

[1] E. DSihaloho, W. Wiksadana, and C. D. Siregar, "Impacts of regional economic factors on the transmission of coronavirus disease 2019 (COVID-19) in Indonesia," Ekonomis: Journal of Economics and Business, vol. 4, no. 2, pp. 397-403, 2020.

[2] S.-C. Sio and Y.-C. So, "The impacts of financial and nonfinancial crises on tourism: evidence from Macao and Hong Kong," Tourism Management Perspectives, vol. 33, Article ID 100628, 2020.

[3] X. Wang, "Research on the economic growth effect of government health expenditure in China-an empirical analysis based on spatial econometric model," Review of Economic Research, vol. 34, pp. 53-64, 2018.

[4] R. J. Barro, "Economic growth in a cross section of countries," The Quarterly Journal of Economics, vol. 106, no. 2, pp. 407-444, 1991.

[5] M. Grossman, "On the concept of health capital and the demand for health," Journal of Political Economy, vol. 80, no. 2, pp. 223-255, 1972.

[6] J. P. Newhouse, "Medical-care expenditure: a cross-national survey," The Journal of Human Resources, vol. 12, no. 1, pp. 115-125, 1977.

[7] S. J. Mushkin, "Health as an investment," Journal of Political Economy, vol. 70, no. 5, pp. 129-157, 1962. 
[8] S. Narayan, P. K. Narayan, and S. Mishra, "Investigating the relationship between health and economic growth: empirical evidence from a panel of 5 Asian countries," Journal of Asian Economics, vol. 21, no. 4, pp. 404-411, 2010.

[9] L. Du, Y. Zhao, and G. Shi, "Total health expenditure in China-econometric analysis and prediction," Chinese Health Economics, vol. 3, pp. 62-64, 2000.

[10] P. M. Bernet and S. R. Singh, "Research on the reform of financial medical and health expenditure based on the perspective of healthy human capital investment," American Public Health Association, vol. 105, no. 2, pp. S260-S267, 2015.

[11] X. Man, Y. Jiang, L. Zhao et al., "Relationship analysis between health expenditure and GDP based on health outcomes," Chinese Journal of Health Policy, vol. 9, no. 7, pp. 66-73, 2016.

[12] G. Mujtaba and S. J. H. Shahzad, "Air pollutants, economic growth and public health: implications for sustainable development in OECD countries," Environmental Science and Pollution Research, vol. 28, no. 10, p. 12686, 2020.

[13] U. G. Moti and D. T. Goon, "Novel Coronavirus disease: a delicate balancing act between health and the economy," Pakistan Journal of Medical Sciences, vol. 36, no. 4, pp. S134-S137, 2020.

[14] R. Aisa and F. Pueyo, "Government health spending and growth in a model of endogenous longevity," Economics Letters, vol. 90, no. 2, pp. 249-253, 2006.

[15] J. Eggoh, H. Houeninvo, and G. A. Sossou, "Education, health and economic growth in African countries," Journal of Economic Development, vol. 40, no. 1, pp. 93-111, 2015.

[16] Y. Liu and K. Zhang, "Empirical analysis on the economic growth effect of public health expenditure in China," Northern Economy, vol. 12, pp. 9-10, 2007.

[17] C. Tao and Y. Wang, "A study on the spatial spillover effect of government health expenditure on regional economy-based on the spatial panel model of 17 cities in Shandong province," East China Economic Management, vol. 33, no. 3, pp. 19-24, 2019.

[18] W. Zhao and D. Wang, "Study on the dynamic relationship among environmental quality, public health expenditure and economic growth-based on the perspective of fiscal decentralization," Jiangxi Social Sciences, vol. 1, pp. 120-131, 2020.

[19] Y. Liu, "Influence of S\&T innovation on S\&T talent aggregation and its spatial spillover effect-an empirical study based on spatial panel Durbin model," Journal of Zhejiang Gongshang University, vol. 5, pp. 80-91, 2019.

[20] X. Zhang, Z. Gang, and X. Dong, "Effects of government healthcare expenditure on economic growth based on spatial Durbin model: evidence from China," Iran Journal of Public Health, vol. 49, no. 2, pp. 283-293, 2020.

[21] T. Mohammad, P. Amir, N. Razieh, and M. R. Gregory, "Evaluating unintended outcomes of regional smart-growth strategies: environmental justice and public health concerns," Transportation Research Part D: Transport and Environment, vol. 49, pp. 280-290, 2016.

[22] B. Jiang, S. Liang, Z.-R. Peng et al., "Transport and public health in China: the road to a healthy future," The Lancet, vol. 390, no. 10104, pp. 1781-1791, 2017.

[23] A. Aminuddian, S. Jaka, and S. Jannahar, "The impact of government spending spillovers on regional economic growth," Montenegrin Journal of Economics, vol. 16, no. 2, pp. 59-76, 2020.

[24] H. Hazwan, "Spatial spillover effects of public health and education expenditures on economic growth: evidence from China's provinces," Post-communist Economies, vol. 2020, Article ID 1722586, 2020.
[25] H. Li and L. Huang, "Health, education, and economic growth in China: empirical findings and implications," China Economic Review, vol. 20, no. 3, pp. 374-387, 2009.

[26] H. Peng and X. Meng, "China's decline of birth rate and economic development," Statistical Research, vol. 31, no. 9, pp. 44-50, 2014.

[27] G. Gu and Y. Wu, "The impact of population age structure change on regional Economy," Economic Geography, vol. 39, no. 1, pp. 47-55, 2019.

[28] M. Wang and C. Tao, "Research on the efficiency of local government health expenditure in China and its spatial spillover effect," Sustainability, vol. 11, p. 2469, 2020.

[29] X. Liu, T. Sun, and Q. Feng, "Dynamic spatial spillover effect of urbanization on environmental pollution in China considering the inertia characteristics of environmental pollution," Sustainable Cities and Society, vol. 53, Article ID 101903, 2020.

[30] X. Xu and Y. Wang, "Study on spatial spillover effects of logistics industry development for economic growth in the Yangtze River Delta city Cluster based on spatial Durbin model," International Journal of Environmental Research and Public Health, vol. 14, p. 1508, 2017.

[31] G. Duanton, "Cumulative investment and spillovers in the formation of technological landscapes," Journal of Industrial Economics, vol. 48, pp. 205-213, 2010.

[32] Y. Su and Y. Yu, "Spatial agglomeration of new energy industries on the performance of regional pollution control through spatial econometric analysis," Science of the Total Environment, vol. 704, Article ID 135261, 2020.

[33] Y. Tian and X. Liu, "The influence of population factors on economic development in western China," Statistics \& Decision, vol. 9, pp. 66-67, 2004. 